\title{
Suitable hepatitis B vaccine for adult immunization in China
}

\author{
Linna Yang ${ }^{1} \cdot{\mathrm{Jun} \mathrm{YaO}^{2} \cdot \mathrm{Jing} \mathrm{Li}^{3} \cdot \text { Yongdi Chen }}^{2} \cdot$ Zheng-gang Jiang ${ }^{2}$. \\ Jing-jing Ren ${ }^{4} \cdot$ Kai-jin $\mathrm{Xu}^{4} \cdot$ Bing Ruan ${ }^{4} \cdot$ Shi-gui Yang ${ }^{4} \cdot$ Bing Wang $^{4}$. \\ Tian-sheng $\mathrm{Xie}^{4} \cdot$ Qian $\mathrm{Li}^{2}$
}

Published online: 8 December 2015

(c) The Author(s) 2015. This article is published with open access at Springerlink.com

\begin{abstract}
The aim of this study was to evaluate, in adults, the immunogenicity of six hepatitis $B$ vaccines with different doses or different manufacturers in the Chinese market and to provide evidence to support adult hepatitis B vaccination. Participants were randomly divided into six groups (I-VI). Six vaccines (4 at $10 \mu \mathrm{g} /$ dose and 2 at $20 \mu \mathrm{g} /$ dose) were administered intramuscularly to healthy adults at 0,1 and 6 month intervals. All participants (16-50 years) who were negative for any hepatitis B virus serological markers were vaccinated. Anti-HBs levels were assessed 1 month and 1 year after the third vaccination. The anti-HBs seroconversion rate (anti-HBs $>10 \mathrm{mIU} / \mathrm{ml}$ ) was $99.4 \%$ (99.9 \% for $10 \mu \mathrm{g}$ dose groups and $97.9 \%$ for $20 \mu \mathrm{g}$ dose groups) 1 month after the third vaccination, and the anti-HBs seroreversion rate was $77.0 \%$ (75.3 and $82.6 \%) 1$ year after the third vaccination $(n=1036)$. One month after completing the vaccinations, the seroconversion rates were not significantly different $(100.0,100.0$, 99.6, 100.0 \%) for the four $10 \mu \mathrm{g}$ dose and two $20 \mu \mathrm{g}$ dose
\end{abstract}

Linna Yang, Jun Yao and Jing Li have contributed equally to this work.

Jun Yao

jyao@cdc.zj.cn

1 School of Medicine, Ningbo University, Ningbo 315211, China

2 Zhejiang Provincial Center for Disease Control and Prevention, Hangzhou 310051, Zhejiang, China

3 Zhejiang Provincial Hospital, Hangzhou 310013, Zhejiang, China

4 State Key Laboratory for Diagnosis and Treatment of Infectious Disease, Key Laboratory of Infectious Diseases, First Affiliated Hospital, School of Medicine, Zhejiang University, Hangzhou 310003, China groups $(99.1,96.9 \%)$. One year after the third vaccination, the group II positive rate was significantly higher than the other three $10 \mu \mathrm{g}$ dose groups, and the group VI positive rate was significantly higher than the other $20 \mu \mathrm{g}$ dose group. Groups II and VI showed a significantly higher positive rate and anti-HBs geometric mean titer (GMT) than the other groups. The anti-HBs level declined with increasing age, and the seroreversion rate and GMT decreased over time. All six vaccines had high anti-HBs seroconversion rates and good immunization effects. The $10 \mu \mathrm{g}$ dose vaccine (Dalian High-Tech) and the $20 \mu \mathrm{g}$ dose vaccine (GlaxoSmithKline) are recommended for adults.

Keywords Adults - Hepatitis B vaccine - Vaccine immunogenicity

\section{Introduction}

Hepatitis B virus (HBV) infection is a current public health problem worldwide [1]. Approximately 780,000 people die each year because of this infection, and more than 240 million have chronic HBV infection, which also serves as the main reservoir for continued HBV transmission [2]. $\mathrm{HBV}$ infection is especially severe in China. According to a national serum epidemiological survey conducted in 2006, the rate of HBsAg carriers is $7.18 \%$ in the general population within the age range of $1-59$ years [3, 4]. Based on this prevalence, over 93 million people are infected with chronic HBV in China [5]. The hepatitis B vaccine was the first vaccine to prevent a chronic disease and a sexually transmitted infection. Hepatitis B vaccination is regarded as the most economical and effective method for preventing and controlling hepatitis B infection because there is no 
satisfactory treatment for chronic hepatitis B infection and related diseases [6-8].

Hepatitis B vaccine has been part of planned immunization management in China since 1992. The hepatitis B infection rate and morbidity in children have decreased significantly with routine neonatal vaccination, but it has not been as successful in adults. Adult hepatitis B immunization in China needs further support. Because adult hepatitis B vaccination has not been systematically carried out in many regions, there are insufficient immunological performance data for the hepatitis $B$ vaccine. To assist with the advancement of the hepatitis $B$ vaccination and control the process in adults, we studied the effects of six different hepatitis B vaccines that are common in the Chinese market: 10 or $20 \mu \mathrm{g}$ dose vaccines from four companies. Adults were given a 10 or $20 \mu \mathrm{g}$ dose of one hepatitis B vaccine at $0-, 1$ and 6-month intervals. The immunogenicity of all six hepatitis $B$ vaccines was evaluated at 1 month and 1 year after completing the vaccination schedule.

\section{Materials and methods}

\section{Study participants}

The study was conducted in seven counties (Deqing, Changxing, Anji, Nanxun, Wuxing, Shaoxing and Tongxiang) in the Zhejiang Province, China. The economic status of the selected counties was similar. The present study was approved by the ethics committee. All participants were willing to participate in the study and they each provided written informed consent before any study-related procedures were performed. We used the questionnaire "Research Questionnaire on Adult Immunization Strategy of Hepatitis B," which contained basic information such as each participant's birth date, age and gender. We collected 3-ml blood samples from each subject prior to vaccination. The first blood draw and the first shot were carried out simultaneously (inoculation after the blood draw). Eligible subjects received three hepatitis $B$ vaccinations, and we collected 3-ml blood samples from each subject at 1 month (210 days from the first dose) and 1 year (545 days from the first dose) after the third vaccination, which were preserved for anti-HBs quantification. Only those participants who were negative for $\mathrm{HBsAg}$, anti-HBs and anti-HBc were analyzed in the study and these participants were divided into six groups, I to VI, based on the different vaccine types. The study was approved by the Institutional Ethics Committee at the Zhejiang Center for Disease Control and Prevention, China. Specific inclusion and exclusion criteria are as follows:

Inclusion criteria (a) age 16-50 years and willing to participate in the study and sign the informed consent form; (b) willing to participate in the follow-up study and to provide the one-month and one-year blood samples after the third dose.

Exclusion criteria (a) reluctant to participate in this study; (b) HBsAg positive and/or anti-HBs positive; (c) history of allergies or severe reaction to vaccination; (d) history of hepatitis B vaccination; (e) history of any kind of vaccination within the previous 4 weeks; (f) high risk of becoming immunologically compromised; (g) previous immune suppressive therapy (intravenous or oral cortisone or chemotherapy); (h) previous immunostimulation therapy; (i) received any kind of observational or experimental drugs during the past 4 weeks; (j) acute illness within the past 7 days; (k) infection that required treatment with antibacterial or antiviral therapy within the past 7 days; (l) fever within the past 3 days (subaxillary temperature $\geq 38{ }^{\circ} \mathrm{C}$ ); (m) known or anticipated immune dysfunction.

\section{Vaccines and vaccination}

The hepatitis B vaccines used in our study were common vaccines in the Chinese market. Subjects were assigned to one of six groups based on the vaccine type: (1) group I: hepatitis B vaccine (lot No. 20090521; dose: $10 \mu \mathrm{g}$; Shenzhen Kangtai Biological Products Co., Ltd., China); (2) group II: hepatitis B vaccine (lot Nos. 2009030906 and 2010010106; dose: $10 \mu \mathrm{g}$; Dalian High-Tech Biopharmaceutical Co., Ltd., China); (3) group III: hepatitis B vaccine (lot No. 200904A3101; dose: $10 \mu \mathrm{g}$; North China Pharmaceutical Company, GeneTech Bio-technology Pharmaceutical Co., Ltd; Chinese Hamster Ovary (CHO)); (4) group IV, hepatitis B vaccine (lot No. XHBVB554AA; dose: $10 \mu \mathrm{g}$; GlaxoSmithKline, UK); (5) group V, hepatitis B vaccine (lot No. 200904A3101; dose: $20 \mu \mathrm{g}$; North China Pharmaceutical Company, GeneTech Bio-technology Pharmaceutical Co., Ltd; CHO); and (6) group VI, hepatitis B vaccine (lot No. XHBVB554AA; dose: $20 \mu \mathrm{g}$; GlaxoSmithKline, UK). Each vaccine was administered intramuscularly in the upper deltoid muscle, according to the recommended immunization procedure, at 0,1 (30 days from the first dose) and 6 (180 days from the first dose) months.

\section{Lab testing}

\section{Sample collection and processing}

Blood samples $(3 \mathrm{ml})$ were collected before vaccination from each qualified participant and at 1 and 12 months after the third vaccination. The samples from each participant were preserved at $-20{ }^{\circ} \mathrm{C}$ for later analysis. All participants remained at the clinic for $30 \mathrm{~min}$ after each injection, to watch for immediate adverse reactions. Frozen 
Fig. 1 Flow chart of the participants enrolled in the study

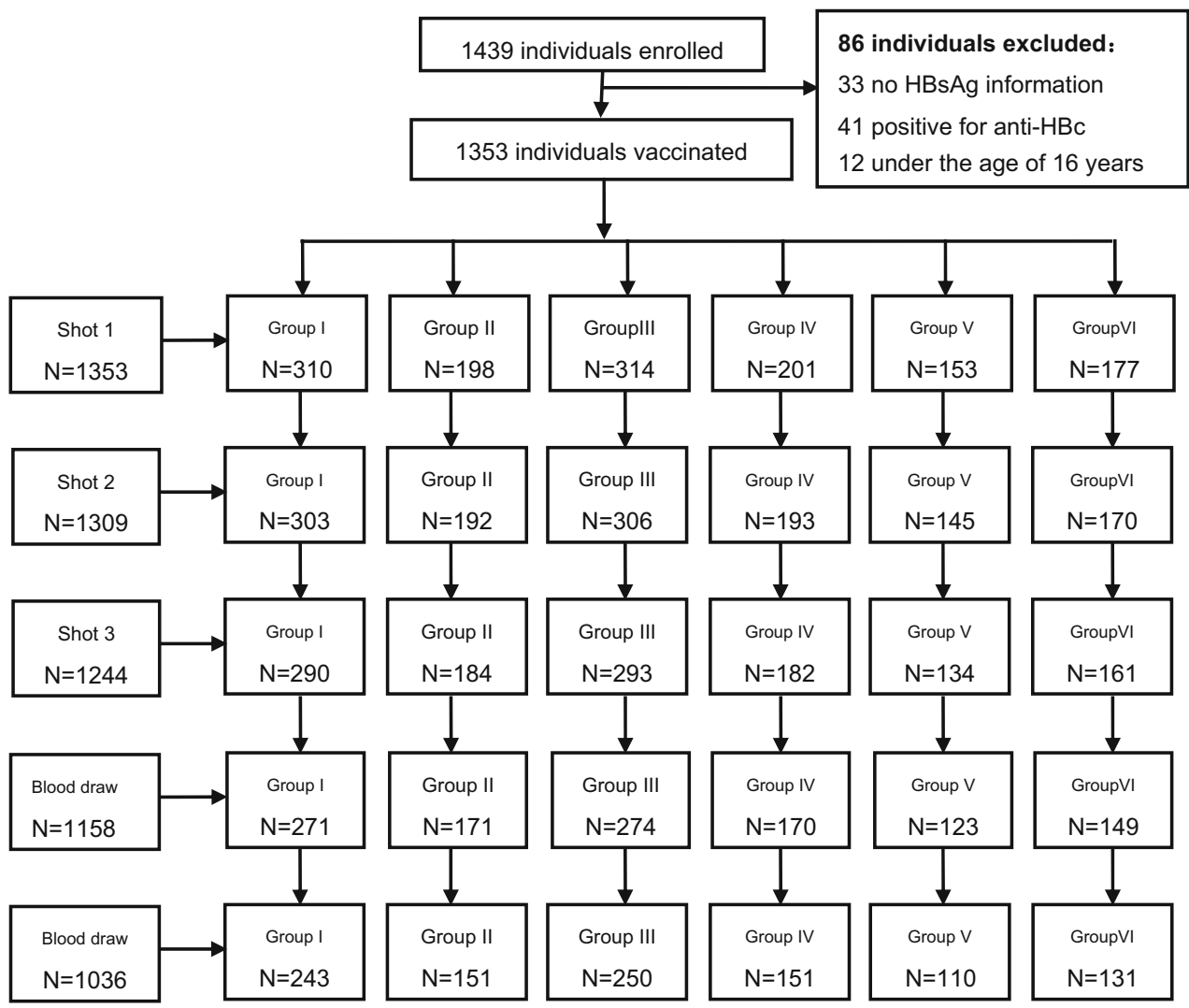

Fisher's exact test was used for enumeration data and analysis of variance was used for measurement data. The relationship between anti-HBs level and the age and antiHBs levels at two time points was compared using a bivariable correlation test. The interactions between age, sex and vaccine were performed using univariate analysis of variance. A two-tailed probability was used in statistical tests, and $\alpha=0.05$ was considered to be significant. The data of antibody titer were normal distribution through a logarithmic conversion.

\section{Results}

\section{Study subject characteristics}

A total of 1439 individuals were enrolled and received the vaccination between March and June 2010, and blood samples were collected at 1 month and 1 year after the final vaccination. There were 403 individuals excluded: 33 subjects had no HBsAg information, 41 subjects were positive for anti-HBc, 12 subjects were under the age of 16 years and 317 subjects were lost to follow-up (Fig. 1). Data from a total of 1036 subjects were analyzed in this study; there were 420 male and 616 female subjects without any reactive hepatitis B serological markers. The average subject age was 32.64 years (range 16.02-49.16 years). There were 243, 
Table 1 Age and sex distribution of study subjects

\begin{tabular}{|c|c|c|c|c|c|c|c|c|c|c|}
\hline \multirow[t]{2}{*}{ Vaccine group } & \multicolumn{2}{|c|}{ Gender } & \multirow[t]{2}{*}{$\chi^{2}$} & \multirow[t]{2}{*}{$p$} & \multicolumn{4}{|l|}{ Age } & \multirow[t]{2}{*}{$\chi^{2}$} & \multirow[t]{2}{*}{$p$} \\
\hline & Male & Female & & & $15-24$ & $25-34$ & $35-44$ & $45-50$ & & \\
\hline I & 99 & 144 & 6.757 & 0.239 & 37 & 97 & 88 & 21 & 22.048 & 0.107 \\
\hline II & 50 & 101 & & & 19 & 62 & 56 & 14 & & \\
\hline III & 107 & 143 & & & 48 & 106 & 77 & 19 & & \\
\hline IV & 65 & 86 & & & 40 & 62 & 39 & 10 & & \\
\hline V & 51 & 59 & & & 21 & 52 & 25 & 12 & & \\
\hline VI & 48 & 83 & & & 31 & 49 & 41 & 10 & & \\
\hline
\end{tabular}

$151,250,110,131$ and 151 subjects in the six groups (I-VI), respectively. There were no statistically significant differences in age or gender between the six groups (Table 1).

\section{Antibody response in the two different vaccine dose groups}

There were 1036 subjects who achieved immune response, with a total seroconversion rate of $99.4 \%$ and an anti-HBs geometric mean titer (GMT) of $429.06 \mathrm{mIU} / \mathrm{ml}$ (95\% CI 381.07-483.10) at 1 month after the third vaccination, and a total positive rate of $77.0 \%$ and an anti-HBs GMT of $47.36 \mathrm{mIU} / \mathrm{ml}(95 \% \mathrm{CI} 41.10-54.58)$ at 1 year after the third vaccination. Both the anti-HBs seroreversion rate and the anti-HBs GMT decreased obviously at 1 year after the third vaccination. There were statistical differences in the seroconversion rates between the $10 \mu \mathrm{g}$ dose vaccine group and $20 \mu \mathrm{g}$ dose vaccine group at 1 month and in the seroreversion rates at 1 year after the third vaccination ( $p=0.003$ and $p=0.019$, respectively). The seroconversion rate in the $10 \mu \mathrm{g}$ dose group was higher than that of $20 \mu \mathrm{g}$ dose group ( 99.9 and $97.9 \%$, respectively) at 1 month after the third vaccination, but the positive rate in the $20 \mu \mathrm{g}$ dose group was higher than that of $10 \mu \mathrm{g}$ dose group at 1 year after the third vaccination $(82.6 \%$ and $75.3 \%$, respectively). The anti-HBs GMTs at the two time points were $429.06 \mathrm{mIU} / \mathrm{ml}(414.28 \mathrm{mIU} / \mathrm{ml}$ for the $10 \mu \mathrm{g}$ dose group and $481.64 \mathrm{mIU} / \mathrm{ml}$ for the $20 \mu \mathrm{g}$ dose group) and $47.36 \mathrm{mIU} / \mathrm{ml}(46.59 \mathrm{mIU} / \mathrm{ml}$ for the $10 \mu \mathrm{g}$ dose group and $50.00 \mathrm{mIU} / \mathrm{ml}$ for $20 \mu \mathrm{g}$ dose group). The differences in the anti-HBs GMTs between the $10 \mu \mathrm{g}$ dose group and the $20 \mu \mathrm{g}$ dose group were not statistically significant at the two time points ( $p=0.293$ and $p=0.680$, respectively).

\section{Comparison of the immunization effects of different $10 \mu \mathrm{g}$ dose vaccines}

The seroconversion rates for the four $10 \mu \mathrm{g}$ dose vaccine groups were 100.0, 100.0, 99.6 and $100.0 \%$, respectively, and the differences in the seroconversion rates between the four groups were not statically significant $(p=1.000$, Fisher's exact test) at 1 month after the third vaccination. The positive rates of the four groups were 74.9, 85.4, 69.2 and $76.2 \%$, respectively, at 1 year after the third vaccination, and the positive rate for group II was significantly higher than the other three groups $(p=0.004)$; group II also showed the least anti-HBs positive proportion decrease over time. The anti-HBs GMTs were $414.28 \mathrm{mIU} / \mathrm{ml}$ (95\% CI 364.88-470.38) and $46.59 \mathrm{mIU} / \mathrm{ml}(95 \% \mathrm{CI}$ 39.30-55.23) at the two time points. The anti-HBs GMTs of the four groups were significantly different at the two time points $(p<0.001)$, and the anti-HBs GMTs of group II were the highest at two time points though it had great decline at 1 year. The anti-HBs GMTs of the four groups were $304.11,906.07,330.33$ and $453.25 \mathrm{mIU} / \mathrm{ml}$ at 1 month after the third vaccination, and 33.60, 98.30, 34.42 and $61.69 \mathrm{mIU} / \mathrm{ml}$ at 1 year after the third vaccination (Table 2; Fig. 2).

\section{Comparison of immunization effects of different $20 \mu \mathrm{g}$ dose vaccines}

The seroconversion rates of the two $20 \mu \mathrm{g}$ dose groups were 99.1 and $96.9 \%$, and the difference was not significant $(p=0.379)$ at 1 month after the third vaccination. The positive rate in group VI was significantly higher than that of group V ( 87.8 and $76.4 \%$, respectively, $p=0.026$ ) at 1 year after the third vaccination. The anti-HBs GMTs were $481.64 \mathrm{mIU} / \mathrm{ml}$ (95\% CI 359.62-645.07) and $50.00 \mathrm{mIU} / \mathrm{ml}$ (95\% CI 39.32-63.58) at the two time points. The anti-HBs GMTs in two groups were significantly different at the two time points $(p<0.001$ and $p<0.002$, respectively), and the anti-HBs GMTs in group VI were higher than that of group $\mathrm{V}$ at 1 month and 1 year after the third vaccination, although there was a large reduction in the anti-HBs GMTs at the second time point. The anti-HBs GMTs in the two groups were 142.98 and $1335.45 \mathrm{mIU} / \mathrm{ml}$ at 1 month after the third vaccination, and 
Table 2 Anti-HBs PSR and GMT of different dose vaccines at two time points

\begin{tabular}{|c|c|c|c|c|c|c|c|c|c|}
\hline \multirow[t]{2}{*}{ Vaccine group } & \multirow[t]{2}{*}{$N$} & \multicolumn{2}{|l|}{$n$} & \multicolumn{2}{|l|}{ PSR (\%) } & \multicolumn{2}{|l|}{ GMT } & \multicolumn{2}{|l|}{$95 \% \mathrm{CI}$} \\
\hline & & One month & One year & One month & One year & One month & One year & One month & One year \\
\hline I & 243 & 243 & 182 & 100.0 & 74.9 & 304.11 & 33.60 & $244.15-378.78$ & $24.36-46.34$ \\
\hline II & 151 & 151 & 129 & 100.0 & 85.4 & 906.07 & 98.30 & $693.63-1183.57$ & $70.18-130.14$ \\
\hline III & 250 & 249 & 173 & 99.6 & 69.2 & 330.33 & 34.42 & $263.61-413.95$ & $25.66-46.17$ \\
\hline IV & 151 & 151 & 115 & 100.0 & 76.2 & 453.25 & 61.69 & $333.10-616.73$ & $41.32-92.12$ \\
\hline Total & 795 & 794 & 599 & 99.9 & 75.3 & 414.28 & 46.59 & $364.88-470.38$ & $39.30-55.23$ \\
\hline$\chi^{2} / F$ & & & & & 13.430 & 13.617 & 8.313 & & \\
\hline$P$ & & & & $1.00^{\mathrm{a}}$ & 0.004 & $<0.001$ & $<0.001$ & & \\
\hline V & 110 & 109 & 84 & 99.1 & 76.4 & 142.98 & 33.28 & $107.43-190.29$ & $22.93-48.31$ \\
\hline VI & 131 & 127 & 115 & 96.9 & 87.8 & 1335.45 & 70.37 & $888.05-2008.24$ & 51.89-95.44 \\
\hline Total & 241 & 236 & 199 & 97.9 & 82.6 & 481.64 & 50.00 & $359.62-645.07$ & $39.32-63.58$ \\
\hline$\chi^{2} / F$ & & & & & 5.421 & 73.267 & 9.685 & & \\
\hline$P$ & & & & $0.379^{\mathrm{a}}$ & 0.026 & $<0.001$ & 0.002 & & \\
\hline
\end{tabular}

${ }^{a}$ Fisher's exact test

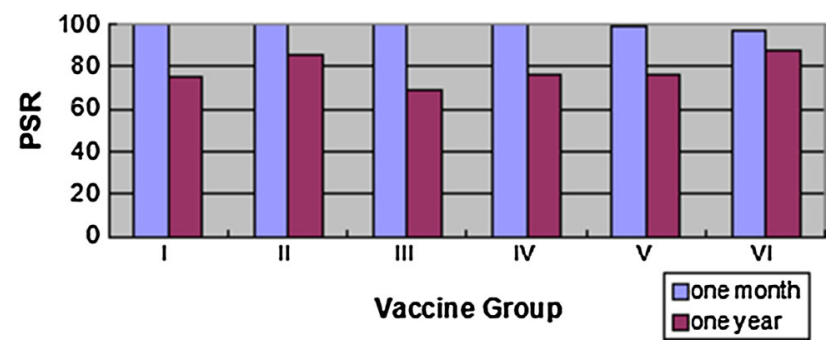

Fig. 2 Positive seroconversion rate (PSR) of different vaccines

33.28 and $70.37 \mathrm{mIU} / \mathrm{ml}$ at 1 year after the third vaccination (Table 2; Fig. 2).

\section{Comparison of the immunization effects in different gender groups after vaccination}

All six vaccines achieved high seroconversion rates in both males and females at 1 month after the third vaccination, and differences in anti-HBs rates for the six vaccines were not statistically significant between the genders ( $p=0.428$, Fisher's exact test, $p=0.464, p=0.139$ ). There were also no statistical differences between anti-HBs positive rates in males and females in the six groups at 1 year after the third vaccination $(p=0.343, p=0.183, p=0.571, p=0.848$, $p=0.670, p=0.237)$.

The anti-HBs GMT in the female group was higher than that of male group at 1 month after the full vaccination: 505.02 and $337.77 \mathrm{mIU} / \mathrm{ml}$, respectively, and the difference was significant ( $p=0.001)$. Only in group II was the anti-HBs GMT statistically different between males and females at the two time points $(p=0.001$ and $p=0.003$, respectively), and the anti-HBs GMTs in the female group were higher than those in the male group: 1239.90 and $142.43 \mathrm{mIU} / \mathrm{ml}$ for females, and 480.82 and $46.48 \mathrm{mIU} / \mathrm{ml}$ for males. The anti-HBs GMT for females in group V was significantly higher than that of males at 1 month after the final vaccination ( $p=0.036)$ : $189.30 \mathrm{mIU} / \mathrm{ml}$ for females and $103.34 \mathrm{mIU} / \mathrm{ml}$ for males (Table 3 ).

\section{Comparison of immunization effects in different age groups after vaccination}

There were no significant differences in the anti-HBs seroconversion rate between the different age groups at 1 month after the third vaccination ( $p=0.361$, Fisher's exact test), and all the six vaccines in different age groups achieved similarly high seroconversion rates: 99.5, 99.8, 98.8 and $100.0 \%$. However, the differences were statistically significant at 1 year after the third vaccination $\left(\chi^{2}=11.182, p=0.011\right)$, with positive rates of 84.7, 77.6, 72.1 and $75.6 \%$. Only in group III the differences between different age groups $(15-24,25-34,35-44,45-50)$ were statistically significant $\left(\chi^{2}=10.044, p=0.018\right)$ and further comparison found that the lower the age groups, the higher were the positive rates $(\alpha=0.01, r=-0.176)$.

The anti-HBs GMTs in the four age groups at 1 month after the third vaccination for all six vaccines were 661.55 , 478.63, 314.89 and $299.89 \mathrm{mIU} / \mathrm{ml}$, and the differences were statistically significant $(F=7.545, p<0.001)$. Thus, the differences at 1 year after the third vaccination were significant $(F=8.132, p<0.001)$, with the anti-HBs GMTs of 75.33, 57.05, 30.27 and $35.59 \mathrm{mIU} / \mathrm{ml}$. Further analysis based on the actual anti-HBs levels and the age 
Table 3 Anti-HBs GMT in different gender groups after vaccination at two time points

\begin{tabular}{|c|c|c|c|c|c|c|c|c|c|c|c|c|c|c|}
\hline \multirow[t]{2}{*}{ Gender } & \multicolumn{2}{|c|}{ Group I } & \multicolumn{2}{|c|}{ Group II } & \multicolumn{2}{|c|}{ Group III } & \multicolumn{2}{|c|}{ Group IV } & \multicolumn{2}{|c|}{ Group V } & \multicolumn{2}{|c|}{ Group VI } & \multicolumn{2}{|c|}{ Total } \\
\hline & $n$ & GMT & $n$ & GMT & $n$ & GMT & $n$ & GMT & $n$ & GMT & $n$ & GMT & $n$ & GMT \\
\hline \multicolumn{15}{|c|}{ One month } \\
\hline Male & 99 & 304.54 & 50 & 480.82 & 107 & 294.52 & 65 & 463.39 & 51 & 103.34 & 48 & 901.29 & 420 & 337.77 \\
\hline Female & 144 & 303.81 & 101 & 1239.90 & 143 & 359.95 & 86 & 445.73 & 59 & 189.30 & 83 & 1676.41 & 616 & 505.02 \\
\hline$F$ & & 0.000 & & 11.642 & & 0.750 & & 0.015 & & 4.522 & & 2.120 & & 10.778 \\
\hline$p$ & & 0.992 & & 0.001 & & 0.387 & & 0.902 & & 0.036 & & 0.148 & & 0.001 \\
\hline \multicolumn{15}{|c|}{ One year } \\
\hline Male & 99 & 34.24 & 50 & 46.48 & 107 & 38.53 & 65 & 58.35 & 51 & 26.23 & 48 & 63.56 & 420 & 41.29 \\
\hline Female & 144 & 33.17 & 101 & 142.43 & 143 & 31.63 & 86 & 64.35 & 59 & 40.88 & 83 & 74.64 & 616 & 50.01 \\
\hline$F$ & & 0.096 & & 9.291 & & 0.427 & & 0.057 & & 1.391 & & 0.251 & & 2.457 \\
\hline$p$ & & 0.924 & & 0.003 & & 0.514 & & 0.812 & & 0.241 & & 0.617 & & 0.117 \\
\hline
\end{tabular}

Table 4 Anti-HBs GMT in different age groups after vaccination at two time points

\begin{tabular}{|c|c|c|c|c|c|c|c|c|c|c|c|c|c|c|}
\hline \multirow[t]{2}{*}{ Age group } & \multicolumn{2}{|c|}{ Group I } & \multicolumn{2}{|c|}{ Group II } & \multicolumn{2}{|c|}{ Group III } & \multicolumn{2}{|c|}{ Group IV } & \multicolumn{2}{|c|}{ Group V } & \multicolumn{2}{|c|}{ Group VI } & \multicolumn{2}{|c|}{ Total } \\
\hline & $n$ & GMT & $n$ & GMT & $n$ & GMT & $n$ & GMT & $n$ & GMT & $n$ & GMT & $n$ & GMT \\
\hline \multicolumn{15}{|l|}{ One month } \\
\hline $15 \sim$ & 37 & 276.00 & 19 & 1278.28 & 48 & 636.80 & 40 & 789.12 & 21 & 161.78 & 31 & 2711.17 & 196 & 661.55 \\
\hline $25 \sim$ & 97 & 390.34 & 62 & 758.99 & 106 & 383.24 & 62 & 496.52 & 52 & 139.97 & 49 & 2276.57 & 428 & 478.63 \\
\hline $35 \sim$ & 88 & 268.97 & 56 & 846.60 & 77 & 217.79 & 39 & 273.60 & 25 & 123.49 & 41 & 462.48 & 326 & 314.89 \\
\hline $45 \sim$ & 21 & 190.45 & 14 & 1632.76 & 19 & 148.63 & 10 & 191.80 & 12 & 171.40 & 10 & 842.12 & 86 & 299.89 \\
\hline$F$ & & 1.366 & & 1.127 & & 5.175 & & 2.890 & & 0.182 & & 5.089 & & 7.545 \\
\hline$p$ & & 0.254 & & 0.340 & & 0.002 & & 0.038 & & 0.909 & & 0.002 & & $<0.001$ \\
\hline \multicolumn{15}{|l|}{ One year } \\
\hline $15 \sim$ & 37 & 42.70 & 19 & 201.15 & 48 & 98.12 & 40 & 110.59 & 21 & 27.71 & 31 & 64.73 & 196 & 75.33 \\
\hline $25 \sim$ & 97 & 48.10 & 62 & 96.95 & 106 & 38.25 & 62 & 66.59 & 52 & 55.05 & 49 & 82.90 & 428 & 57.05 \\
\hline $35 \sim$ & 88 & 25.33 & 56 & 65.43 & 77 & 18.58 & 39 & 33.84 & 25 & 10.40 & 41 & 66.78 & 326 & 30.27 \\
\hline $45 \sim$ & 21 & 13.74 & 14 & 201.46 & 19 & 16.49 & 10 & 38.72 & 12 & 58.46 & 10 & 50.68 & 86 & 35.59 \\
\hline$F$ & & 2.005 & & 1.868 & & 5.935 & & 1.641 & & 4.889 & & 0.287 & & 8.132 \\
\hline$p$ & & 0.114 & & 0.138 & & 0.001 & & 0.182 & & 0.003 & & 0.834 & & $<0.001$ \\
\hline
\end{tabular}

found that the anti-HBs level was related to age at two time points: $r=-0.153(\alpha=0.01) 1$ month after the full vaccination and $r=-0.128(\alpha=0.01) 1$ year after the full vaccination, and the younger the age, the higher the anti-HBs level (Tables 4, 5).

No spontaneous adverse effects related to the six vaccines were reported by the participants.

\section{Discussion}

An American study reported that the 25- to 44-year-old age group showed the highest proportion of new hepatitis B infections [9], and once infected by hepatitis $B$, these patients' children may be at high risk of hepatitis B infection because marriage and child-rearing are common in this age population $[10,11]$. Hepatitis $B$ vaccination could lead to a $38-47 \%$ reduction in future HBV-related deaths [12]. Currently, the recommended hepatitis B vaccination dose abroad for healthy adults is $20 \mu \mathrm{g}$, and previous studies found that the immunological effect of $20 \mu \mathrm{g}$ dose vaccination for adults was better than that of $10 \mu \mathrm{g}$ dose vaccination [13-16]. The common healthy adult hepatitis B vaccine dose is $10 \mu \mathrm{g}$ in China. We included both $10 \mu \mathrm{g}$ dose vaccines and $20 \mu \mathrm{g}$ dose vaccines in our study, and all six of the vaccines were administered to six groups: groups I-IV included four $10 \mu \mathrm{g}$ dose vaccines (Shenzhen Kangtai, Dalian High-Tech, North China 
Table 5 A bivariate correlation on age and anti-HBs level for different vaccines

\begin{tabular}{|c|c|c|c|c|c|c|c|}
\hline & Group I & Group II & Group III & Group IV & Group V & Group VI & Total \\
\hline$r$ (one month) & -0.060 & 0.034 & $-0.237^{\mathrm{a}}$ & $-0.255^{\mathrm{a}}$ & 0.013 & $-0.379^{\mathrm{a}}$ & $-0.153^{\mathrm{a}}$ \\
\hline$r$ (one year) & -0.144 & -0.081 & $-0.235^{\mathrm{a}}$ & -0.042 & -0.012 & 0.073 & $-0.128^{\mathrm{a}}$ \\
\hline
\end{tabular}

${ }^{\mathrm{a}} \alpha=0.01$

Table 6 Anti-HBs PSR and GMT of six vaccines separated by county at two time point

\begin{tabular}{|c|c|c|c|c|c|c|c|c|}
\hline \multirow[t]{2}{*}{ Vaccine group } & \multirow[t]{2}{*}{ County } & \multirow[t]{2}{*}{$N$} & \multicolumn{2}{|l|}{ PSR ( \%) } & \multirow[t]{2}{*}{$p$} & \multicolumn{2}{|l|}{ GMT } & \multirow[t]{2}{*}{$p$} \\
\hline & & & One month & One year & & One month & One year & \\
\hline \multirow[t]{2}{*}{ I } & 1 & 97 & 100.0 & 82.5 & \multirow[t]{3}{*}{0.026} & 248.66 & 38.22 & \multirow[t]{3}{*}{0.014} \\
\hline & 5 & 146 & 100.0 & 69.9 & & 347.62 & 30.85 & \\
\hline II & 2 & 151 & 100.0 & 85.4 & & 906.07 & 98.30 & \\
\hline \multirow[t]{2}{*}{ III } & 3 & 70 & 100.0 & 70.0 & \multirow[t]{5}{*}{$>0.05$} & 328.32 & 36.43 & \multirow[t]{5}{*}{0.004} \\
\hline & 7 & 180 & 99.4 & 68.9 & & 331.13 & 33.67 & \\
\hline IV & 7 & 151 & 100.0 & 76.2 & & 453.25 & 61.69 & \\
\hline V & 4 & 110 & 99.1 & 76.4 & & 142.98 & 33.28 & \\
\hline VI & 6 & 131 & 96.9 & 87.8 & & 1335.45 & 70.37 & \\
\hline
\end{tabular}

Pharmaceutical and GlaxoSmithKline, respectively), and groups V and VI included two $20 \mu \mathrm{g}$ dose vaccines (North China Pharmaceutical and GlaxoSmithKline).

The six vaccines used in this study were administered intramuscularly to qualified participants, and immunogenicity was demonstrated in all participants; the seroconversion rates were obtained at 1 month and the seroreversion rates were obtained at 1 year after the third and final vaccination. Previous research has shown that, in general, hepatitis B vaccination programs (0-1-6 schedule) in healthy adults induce seroconversion rates of over $90 \%$ [17]. In our study, the average seroconversion rate was $99.4 \%$ and the anti-HBs GMT was $429.06 \mathrm{mIU} / \mathrm{ml}$ at 1 month after the third vaccination. The total positive rate was $77.0 \%$ and the anti-HBs GMT was $47.36 \mathrm{mIU} / \mathrm{ml}$ at 1 year after the third vaccination. An anti-HBs level $\geq 10 \mathrm{mIU} / \mathrm{mL}$ is considered to confer vaccine-elicited protection against HBV infection [18, 19], and thus, all six hepatitis B vaccines in this study achieved good immunization effects at both time points, although there was an obvious decrease in the positive rate after 1 year. The decrease in anti-HBs protective rate depended upon the peak anti-HBs value [20]. A bivariate correlation between the anti-HBs level 1 month after the full vaccination and the anti-HBs level 1 year after the full vaccination found that the higher the anti-HBs level at 1 month was, the higher the anti-HBs level at 1 year was $(r=0.430)$. In the present study, the $10 \mu \mathrm{g}$ dose vaccines obtained better immune seroconversion than the $20 \mu \mathrm{g}$ dose vaccines at 1 month after the third vaccination. For the reason of large sample data, little difference may be tested when analyzed. According to the seroconversion rates 1 month after the full vaccination, both $10 \mu \mathrm{g}$ dose vaccine and $20 \mu \mathrm{g}$ dose vaccine could achieve good immune response. It was also shown that, in China, the $10 \mu \mathrm{g}$ dose of hepatitis B vaccines could obtain good protective effects [21]. The differences in anti-HBs levels between different vaccines were significant at the two time points. The positive rate for the Dalian High-Tech vaccine (Lot Nos. 2009030906 and 2010010106; dose: $10 \mu \mathrm{g}$; Dalian High-Tech Biopharmaceutical Co., Ltd., China) was the highest among the four $10 \mu \mathrm{g}$ dose vaccines at the 1 year time point after the third vaccination, while the seroconversion of subjects who received this vaccine was not significantly different at 1 month after the third vaccination, which may show that this vaccine has good stability. The positive rate of the GlaxoSmithKline vaccine (lot No. XHBVB554AA; dose: $20 \mu \mathrm{g}$; GlaxoSmithKline, UK) was significantly higher than another $20 \mu \mathrm{g}$ dose vaccine at 1 year after the third vaccination, and this may also suggest that the vaccine has good stability.

In the present study, all six vaccines produced good immune effects for both genders and subjects of different ages. The anti-HBs GMTs for females were higher than that for males at 1 month after the third vaccination, and the anti-HBs levels showed a negative correlation with age 1 month after the full vaccination. These results indicate that the anti-HBs level attained after the third vaccination was related to age, which was consistent with previous studies [22]. Beside the independent effects of the three 
factors (age, vaccine and sex) on the anti-HBs levels, the interaction was found between age group and vaccine type 1 month after the full vaccination through further analysis $(F=1.942, p=0.017)$, and younger age can contribute to the enhancement effect of vaccines. Apart from male gender and older age, well-known factors that lead to low hepatitis $\mathrm{B}$ vaccine immunogenicity include host-related obesity (including those who are non-obese but overweight), smoking, alcohol intake, chronic diseases (cirrhosis, diabetes, mellitus, chronic renal failure), immune suppression, genetic variation, injection site and storage conditions [23-32].

In our study, we selected six different vaccines and evaluated the immune effects at two time points. The immune effect of the $10 \mu \mathrm{g}$ dose hepatitis B vaccine produced by Dalian High-Tech was better than that of the other three $10 \mu \mathrm{g}$ dose vaccines, and the immune effect of the $20 \mu \mathrm{g}$ dose vaccine produced by GlaxoSmithKline was better than the other $20 \mu \mathrm{g}$ dose vaccine produced by the North China Pharmaceutical Company. Different counties where the same vaccine was used had the similar immune response (Table 6). The same vaccines vaccinated in other studies also achieved similar good antibody responses [3336]. They produced high anti-HBs seroreversion/positive rates and anti-HBs GMTs, and persistent immune protection would be extended as a result of the high anti-HBs peak value [32]. The $10 \mu \mathrm{g}$ dose of hepatitis B vaccine produced by Dalian High-Tech and the $20 \mu \mathrm{g}$ dose vaccine produced by GlaxoSmithKline are recommended for vaccination of adults.

There are some limitations of our study. First, the number of participants lost to follow-up was relatively large and we could not obtain the anti-HBs results in participants who were missing at 1 year, but the subjects who were lost follow-up had similar demographic characteristics as subjects who finished the one-year follow-up, and it is unlikely that a difference in the persistence of immunity would have occurred if less subjects had been lost to follow-up. In addition, further study is required to analyze the trend in seroreversion rates, and more time points such as 1 month after the first dose and the second dose should be individually analyzed.

Acknowledgments We are grateful to the participants of this study and we appreciate the coordination and support of the doctors from the Centers for Diseases Control and Prevention in Deqing, Changxing, Anji, Nanxun, Wuxing, Shaoxing and Tongxiang counties of Zhejiang Province. Project supported by the National Scientific and Technological Major Project of China (No. 2013ZX10004-904).

Open Access This article is distributed under the terms of the Creative Commons Attribution 4.0 International License (http:// creativecommons.org/licenses/by/4.0/), which permits unrestricted use, distribution, and reproduction in any medium, provided you give appropriate credit to the original author(s) and the source, provide a link to the Creative Commons license, and indicate if changes were made.

\section{References}

1. Ganem D, Prince AM. Hepatitis B virus infection-natural history and clinical consequences. N Engl J Med. 2004;350:1118-29.

2. WHO (2013) No. 204. http://www.who.int/mediacentre/factsh eets/fs204/en/.

3. Liang X, Bi S, Yang W, Wang L, Cui G, Cui F, Zhang Y, Liu J, Gong X, Chen Y, et al. Epidemiological serosurvey of hepatitis B in China-declining HBV prevalence due to hepatitis B vaccination. Vaccine. 2009;27:6550-7.

4. Liang X, Bi S, Yang W, Wang L, Cui G, Cui F, Zhang Y, Liu J, Gong X, Chen Y, et al. Evaluation of the impact of hepatitis B vaccination among children born during 1992-2005 in China. J Infect Dis. 2009;200:39-47.

5. Lu FM, Zhuang H. Management of hepatitis B in China. Chin Med J (Engl). 2009;122:3-4.

6. Chang MH, Hadzic D, Rouassant SH, Jonas M, Kohn IJ, Negro F, Roberts E, Sibal A. Acute and chronic hepatitis: working group report of the second world congress of pediatric gastroenterology, hepatology, and nutrition. J Pediatr Gastroenterol Nutr. 2004; 39: 584-588.

7. Weinbaum CM, Williams I, Mast EE, Wang SA, Finelli L, Wasley A, Neitzel SM, Ward JW. Recommendations for identification and public health management of persons with chronic hepatitis B virus infection. MMWR Recomm Rep. 2008;57:1-20.

8. Shen LZ, Yao J. Study development on booster immune strategy of hepatitis B vaccine. Zhejiang J Prevent Med. 2011;23:22-5 (in Chinese).

9. Daniels D, Grytdal S, Wasley A. Surveillance for acute viral hepatitis-United States, 2007. MMWR Surveill Summ. 2009;58: $1-27$.

10. Guo Z, Wei J, Feng L, Wang B, Zhao N, Wang S. Study on influence factors of $\mathrm{HBV}$ intrauterine infection in newborns of pregnant women with HBsAg. J Hyg Res. 2011;40:180-3.

11. He J-y, Zhand Y-h, Zhang Y-l, Huang H-f. Instructional significance of HBV-DNA load in maternal milk on breastfeeding of postpartum women infected with HBV. Chin J Prev Med. 2011;45:1004-6.

12. Goldstein ST, Zhou F, Hadler SC, Bell BP, Mast EE, Margolis HS. A mathematical model to estimate global hepatitis B disease burden and vaccination impact. Int J Epidemiol. 2005;2005 (34):1329-39.

13. Keating GM, Noble S. Recombinant hepatitis B vaccine (Engerix-B: a review of its immunogenicity and protective efficacy against hepatitis B). Drugs. 2003;60:1021-51.

14. Idilman R, De MN, Colantoni A, Nadir A, van Thiel DH. The effect of high dose and short interval HBV vaccination in individuals with chronic hepatitis C. Am J Gastroenterol. 2002;97: 435-9.

15. Ul-Haq N, Hasnain SS, Umar M, Abbas Z, Valenzuela-Silva C, Lopez-Saura P. Immunogenicity of 10 and 20 microgram hepatitis B vaccine in a two-dose schedule. Vaccine. 2003;21: 3179-85.

16. Chiaramonte M, Majori S, Ngatchu T, Moschen ME, Baldo V, Renzulli G, et al. Two different dosages of yeast derived recombinant hepatitis B vaccines: a comparison of immunogenicity. Vaccine. 1996;14:135-7.

17. Maynard JE, Kane MA, Alter MJ, Halder SC. Control of hepatitis B by immunization: global perspectives. In: Vyas GN, Dienstag 
JL, Hoofnagle JH, editors. Viral hepatitis and liver disease. New York: Grune and Stratton; 1988. p. 967-9.

18. Mast EE, Weinbaum CM, Fiore AE, Alter MJ, Bell BP, Finelli L, et al. A comprehensive immunization strategy to eliminate transmission of hepatitis B virus infection in the United States: recommendations of the Advisory committee on immunization practices (ACIP) part II: immunization of adults. MMWR Recomm Rep. 2006;55:1-33.

19. Szmuness W, Stevens CE, Zang EA, Harley EJ, Kellner A. A controlled clinical trial of the efficacy of the hepatitis $B$ vaccine (Heptavax B): a final report. Hepatology. 1981;1:377-85.

20. Jilg W, Schmidt M, Deinhardt F. Persistence of specific antibodies after hepatitis B vaccination. J Hepatol. 1988;6:201-7.

21. Gong XY, Zhong JY. Evaluation of immunogenicity of $10 \mu \mathrm{g}$ recombinant yeast-derived hepatitis $\mathrm{B}$ vaccine in adults. China Prevent Med. 2009;10:934-6 (in Chinese).

22. Coates T, Wilson R, Patrick G, Andre F, Watson V. Hepatitis B vaccines: assessment of the seroprotective efficacy of two recombinant DNA vaccines. Clin Ther. 2001;23:392-403.

23. Weber DJ, Rutala WA, Samsa GP, Santimaw JE, Lemon SM. Obesity as a predictor of poor antibody response to hepatitis B plasma vaccine. JAMA. 1985;254:3187-489.

24. Fisman DN, Agrawal D, Leder K. The effect of age on immunologic response to recombinant hepatitis $B$ vaccine: a meta-analysis. Clin Infect Dis. 2002;35:1368-75.

25. Shaw FE Jr, Guess HA, Roets JM, et al. Effect of anatomic injection site, age and smoking on the immune response to hepatitis B vaccination. Vaccine. 1989;7:425-30.

26. Feng Y, Yan B, Zhang L, Lu L-j, Liu J-y, Gong X-h, Cui F-q, Linag X-f, Chen S-y, Xu A-q. Study on antibody response to revaccination of hepatitis $\mathrm{B}$ vaccine among firstly low-response adults. Chin J Prev Med. 2012;46:813-7.

27. Averhoff F, Mahoney F, Coleman P, Schatz G, Hurwitz E, Margolis H. Immunogenicity of hepatitis B vaccines. Implications for persons at occupational risk of hepatitis B virus infection. Am J Prev Med. 1998;15:1-8.
28. Lin HH, Liao HW, Lin SK. Wang LY.HLA and response to booster hepatitis B vaccination in anti-HBs-seronegative adolescents who had received primary infantile vaccination. Vaccine. 2008;26:3414-20.

29. Wang C, Tang J, Song W, Lobashevsky E, Wilson CM, Kaslow RA. HLA and cytokine gene polymorphisms are independently associated with responses to hepatitis B vaccination. Hepatology. 2003;39:978-88.

30. Kruger A, Adams P, Hammer J, Bocher WO, Schneider PM, Rittner C, et al. Hepatitis B surface antigen presentation and HLA-DRB1*-lessons from twins and peptide binding studies. Clin Exp Immunol. 2005;140:325-32.

31. Estévez ZC, Betancourt AA, González VM, Baile NF, Silva CV, Bernal $\mathrm{FH}$, et al. Immunogenicity and safety assessment of the Cuban recombinant hepatitis B vaccine in healthy adults. Biologicals. 2007;35:115-22.

32. DeRave S, Heijtink RA, Bakker-Bendik M, Boot J, Schalm SW. Immunogenicity of standard and low dose vaccination using yeast-derived recombinant hepatitis B surface antigen in elderly volunteers. Vaccine. 1994;12:532-4.

33. Yu SF, Ling J, Qian XP, Hu ZF, Liu T. Three adult immunization schedules of hepatitis B vaccine. Dis Surveill. 2012;27:604-6 (in Chinese)

34. Jiang ZG, Chen EF, Li Q, et al. A study on effect of booster immunization for hepatitis B among children. Zhejiang J Prev. 2011;23:1-4 (in Chinese).

35. Chen SY, Wang XC, Dong XL, Xu HT, Wang FD, Tang ZF, Wang XL, Fan JL. Effects of two immunization schedules of recombinant yeast-derived hepatitis B vaccine for adults. Chin Prev Med. 2013;14(2):96-8 (in Chinese).

36. Zhang L, Liu J, Lu J, Yan B, Song L, Li L, Cui F, Zhang G, Wang $\mathrm{F}$, Liang $\mathrm{X}, \mathrm{Xu} \mathrm{A}$. Antibody response to revaccination among adult non-responders to primary hepatitis B vaccination in China. Hum Vaccin Immunother. 2015;7:1-7. 